\title{
Modification of the Surface Properties of Core-Shell Semiconductors and Their Effects on the Photodecolorization Activity and Adsorption
}

\author{
Shahab K. Asl \\ Faculty of Mechanical Engineering, Department of Ceramic Engineering, University of Tabriz, Tabriz, Iran \\ Email:sh.kh.asl@tabrizu.ac.ir
}

How to cite this paper: Asl, S.K. (2017) Modification of the Surface Properties of Core-Shell Semiconductors and Their Effects on the Photodecolorization Activity and Adsorption. Modern Research in Catalysis, 6, 65-72.

http://dx.doi.org/10.4236/mrc.2017.61005

Received: December 8, 2016

Accepted: January 19, 2017

Published: January 22, 2017

Copyright $\odot 2017$ by author and Scientific Research Publishing Inc. This work is licensed under the Creative Commons Attribution International License (CC BY 4.0).

http://creativecommons.org/licenses/by/4.0/

c) (i) Open Access

\begin{abstract}
Semiconductor-based photocatalysts have been extensively studied for oxidative photodestruction of organic pollutants in wastewaters, releasing non-toxic substances such as Azo dyes. Various synthesized catalyst specimens were characterized to determine the correlation between preparation conditions (catalyst type, dopant, microstructure, preparation routs, optical and physicochemical properties) on the photocatalytic activity. Some researchers focused on the process parameters to optimize them to reach higher photoactivity. The specific surface areas, crystalline size, charge and pretreatment of the surface have significant effects on the physical and photocatalytic properties of the semiconductors. The surface sites of catalyst $\left(\mathrm{TiO}_{2}\right)$ were modified by doping $\mathrm{ZnS}$ nanoparticles in the form of Core-Shell structure and the photocatalytic activities were determined by using color degradation and hydrogen production tests. The dye adsorption isotherms of photocatalyst were determined using UV-Vis spectroscopy. The specific surface properties were determined from BET, Zeta meter and Particle size analyzer tests. Photocatalytic decolorization of AR and water splitting test were applied to understand the relation between the surface properties and the photocatalytic activity. The result indicated that core-shell prepared samples had different surface suitable sites to cooperate in photocatalytic reaction.
\end{abstract}

Keywords

$\mathrm{ZnS}, \mathrm{TiO}_{2}$, Nanocomposite, Core-Shell, Surface Properties, Photocatalysis

\section{Introduction}

Photocatalysis has recently become a common green nano material. Its applica- 
tion in advanced oxidation processes was rapidly increased, because of world's main problems, energy and fuel. The control of organic, inorganic and bacterial pollutions in water and air is an important measure in environmental protection [1] [2] [3].

The kinetic of heterogeneous catalysts like photocatalysts is included five steps. These are: 1) diffusion of reactants to the surface; 2) adsorption of reactants onto the surface; 3 ) reaction on the surface. This step in photocatalytic reaction proceed mainly by the contributions of active oxygen species, such as hydroxyl radical, $\mathrm{OH}^{-}$, superoxide radical, $\mathrm{O}_{2}^{-}$and hydrogen peroxide, $\mathrm{H}_{2} \mathrm{O}_{2}$; 4) desorption of products from the surface; and 5) diffusion of products from the surface [1].

In a photocatalysis system, photo irradiation inducing molecular transformations or reactions takes place at the surface of a heterogeneous catalyst; therefore, the surface properties and sites are so important [4].

The composite materials are engineered or naturally occurring materials made from two or more constituent materials with significantly interface between matrix and reinforcements [5]. The interest in nano composite materials stems from the fact that their totally properties are a function of their size, composition, interface and microstructurs. Therefore, main strategies are required to prepare suitable nano composites reliably and predictably in order to optimize properties by nanotechnology. In this way, many nano composite structures were developed, consisting of nano structured particles or bulks. When two compounds were in the nano size scale, different composites were developed like bimetals, core-shells or multi layers. Similar to other nano materials, many processes were used to prepare these composites [6], like co precipitation, sol gel, solvothermal, microemulsion and hybrid methods and some self assembled techniques. Composite powders are utilized in the areas of coatings, electronics, catalysis, separations and drugs. The beginning of core-shell particles is also of interest from a fundamental and academic viewpoint, especially in the areas of composite and surface science. The core-shell structure is a composite in nano scale which both substrate and thin layer or individual particles on it are in nano size. They are applicable as model systems to investigate factors governing colloidal interactions and stabilization and to find valuable information on the properties of composite dispersions as nano particle engineering.

Controlled properties of surface in hetro catalysts are often accomplished by coating or encapsulating them within a shell of a preferred material, or from the other viewpoint, controlling the morphology and size of the coating by using templates is done for some applications. For example, the shell could alter the charge of the surface, functionality, and reactivity of the surface sites, and could enhance the stability and dispersibility of the colloidal powders. Magnetical, optical, or catalytical functions may be readily imparted to the dispersed colloidal matter depending on the properties of the coating. Encasing nano materials in a shell may also protect the core from extraneous environmental changes in drug delivery. 
Core-shell composites often show functionalized specifical properties over their single-component counterparts, and hence are potentially useful in a wide range of applications [5].

Optimization of the specific characteristics of the surface of nano materials through coating processes is the goal of many researchers. Polymer coating, inorganic, composite coating and Biomacromolecule Layer are used as a shell in synthesized core-shell particles in the nanometers size to multilayer of thin films. In the field of catalytic materials, applications of onion shape materials were very interests. Optimization of catalyst properties by controlling the specific surface area, the band gap position by quantum dot shells, the stability of catalyst in different conditions, and the reaction between electron and hole in the semiconductor powders were the goal of these materials. $\mathrm{ZnO}$, CdSe, CdTd, CdS, ZnTe and similar compounds [7] [8] [9] were applied as a core shell system with different groups.

Photocatalytic decomposition of dye near the surface of the photocatalyst nanoparticles is related to their band gap energy and recombination sites. In this paper, the nano particle size effect on the optical activity studied and demonstrated significant increase in the resulting photocatalysis with decreasing the size of such immobilized nanoparticles for the first time. The higher levels of photocatalytic activity seen in the case of nano composites in compare with the cases of only $\mathrm{TiO}_{2}$ with the same total metal-oxide nano particle concentration.

\section{Materials and Methods}

In the powder preparation procedure, nano size $\mathrm{TiO}_{2}$ were used by hydrothermally prepared anatase powders according to kolenko method [10]. Then, the mixtures of ethanol $\left(\mathrm{C}_{2} \mathrm{H}_{5} \mathrm{OH}\right)$ and triethanolamine (TEA, $\left.\mathrm{C}_{6} \mathrm{H}_{15} \mathrm{NO}_{3}\right)$ and $\mathrm{TiO}_{2}$ powders were prepared. Thiocarbamide, $\left(\mathrm{CH}_{3} \mathrm{COO}\right)_{2} \mathrm{Zn} \cdot 2 \mathrm{H}_{2} \mathrm{O}$ and water as the raw materials employed to produce $\mathrm{ZnS}$ shell's according to $\mathrm{Xu}$ method [11]. Zinc acetate dehydrate $\left[\mathrm{Zn}\left(\mathrm{CH}_{3} \mathrm{COO}\right)_{2} \cdot 2 \mathrm{H}_{2} \mathrm{O}\right]$ crystals were added to the initial solution under $400 \mathrm{rpm}$ agitation until the $\mathrm{pH}$ of the solution was reached to about 9 . To increase the $\mathrm{pH}$ of solution up to 11 , sodium hydroxide $(\mathrm{NaOH})$ solution was added. The resultant solution was then transferred into an autoclave at $140^{\circ} \mathrm{C}$ for $5 \mathrm{~h}$. After the reaction was completed the autoclave was cooled down to room temperature naturally. To increase the precipitation rate and remove unwanted impurities, the precipitates were filtered, sonicated and washed with deionized water for several times and dried at $60^{\circ} \mathrm{C}$ in an oven. The obtained powders with $\left(0,50,80\right.$ and 100 mole $\left.\% \mathrm{TiO}_{2}\right)$ were prepared.

The nano composites with $(0.5 \% \mathrm{Pt})$ prepared by wet impregnation methods used as photocatalysis reaction. Other chemicals used in the experiments were analytical grade. X ray diffraction (XRD; SIEMENS D500; $1.784 \mathrm{~nm} \mathrm{CuK}_{a}$ ), used to identify the crystalline size by means of the Scherrer's equation, the ZnS, rutile and anatase phases was determined by internal standards The average specific surface area and open pore size distribution of powder was determined by analyzing the $\mathrm{N}_{2}$ adsorption isotherm and calculated with the BET and BJH equa- 
tions. The surface and particle morphology characterizations were also did by using transmission electron microscopy (TEM, Jcol Co., 1200EX, Japan). The surface charge was characterized by (Malvern, Zetasizer 3000HS).

The photocatalytic activities and adsorption isotherms of the samples were calculated in the photo degradation of aqueous Acid Red 14 Azar Rang co. (Iran), and water splitting in fujishima's reactor [3] which was used directly without further purification. In a typical procedure, the investigated photocatalyst sample was added into a $500 \mathrm{~mL}$ reactor which contains Azo dye. The concentration of the photocatalyst was estimated by UV-Vis spectrophotometer (UV-Vis 2500, Shimadzu, Japan). The $\mathrm{pH}$ value of the reaction batch reactor was about seven. The suspension was then transferred into the transparent photoreactor and irradiated with a high-pressure UV-C lamp. Samples were obtained at an interval of $10 \mathrm{~min}$ and the absorbencies of the samples were checked after paper filtering. Hydrogen production test was carrying out in a sealed batch pyrex reactor with monometer and septum link for sampling. Gas chromatograph (HP 4890, GC) applied to calculate hydrogen production rates.

\section{Results and Discussion}

The surface properties of powders are controlled by the preparation conditions. The crystalline size, phase composition (derived from XRD) and specific surface area (derived from BET) of nano size powders are given in Table 1. These powders applied to characterize photocatalytic activities with various phases' ratios, crystalline size, and reaction time. The phase ratios did not changed by secondary heat treatment and Shell preparation process adjust to reach similar crystalline size and surface area [4].

Figure 1 illustrates TEM images of powders synthesized at different conditions with different precursors. The images show that as-synthesized powders have different particle morphology. The $\mathrm{ZnS}$ and $\mathrm{TiO}_{2}$ powders consist of cubic like and spherical particles, respectively but composite powders seem to be similar to core shapes. Those images clearly show that with adjusting components ratio, the microstructure and surface of powders are controlled.

Table 2 shows the effect of particles on the rates of photodegradiation of AR

Table 1. Phase composition and structural properties of powders synthesized by hydrothermal method.

\begin{tabular}{|c|c|c|c|c|}
\hline Reference & Synthesis & Phase composition & $\begin{array}{l}\text { Particle size } \\
\mathrm{nm} \text { (XRD) }\end{array}$ & $\begin{array}{l}\mathrm{BET}, \\
\mathrm{m}^{2} \cdot \mathrm{g}^{-1}\end{array}$ \\
\hline A & $\begin{array}{l}\text { TiCl4 solution, } \mathrm{HCl} \\
\text { 160C, } 24 \mathrm{~h} \text {, TEA }\end{array}$ & Anatase $100 \%$ & 20 & 80 \\
\hline A20Z & $\begin{array}{c}\mathrm{A}+20 \% \mathrm{Zn}(\mathrm{Ac}) \\
\text { hydrothermal }\end{array}$ & Anatase $80 \%+\mathrm{ZnS} 20 \%$ & $\sim 20$ & 85 \\
\hline A50Z & $\begin{array}{c}\mathrm{A}+50 \% \mathrm{Zn}(\mathrm{Ac}) \\
\text { hydrothermal }\end{array}$ & Anatase $50 \%+$ ZnS 50\% & $\sim 20$ & 70 \\
\hline $\mathrm{Z}$ & $\mathrm{Zn}(\mathrm{Ac})$ hydrothermal & ZnS 100\% & 20 & 50 \\
\hline
\end{tabular}


Table 2. Decolorization and hydrogen production rates, adsorption wavelength and surface charge of composite powders synthesized by hydrothermal method.

\begin{tabular}{ccccc}
\hline Reference & $\begin{array}{c}\text { Decolorization } \\
\text { rate }\left(\mathrm{min}^{-1}\right)\end{array}$ & $\begin{array}{c}\text { Hydrogen } \\
\text { production rate } \\
\left(\text { micro } \mathrm{mol} \mathrm{H}_{2} / \text { gr cat.h }\right)\end{array}$ & $\begin{array}{c}\text { Adsorption } \\
\text { wavelengths } \\
(\mathrm{nm})\end{array}$ & $\begin{array}{c}\text { Surface } \\
\text { change }(\mathrm{mV})\end{array}$ \\
\hline $\mathrm{A}$ & 0.23 & 532 & 361 & 2.7 \\
$\mathrm{~A} 20 \mathrm{Z}$ & 0.49 & 609 & 320 & 12.4 \\
$\mathrm{~A} 50 \mathrm{Z}$ & 0.37 & 281 & 332 & 24.1 \\
$\mathrm{Z}$ & 0.20 & 0 & 355 & 29.5 \\
\hline
\end{tabular}
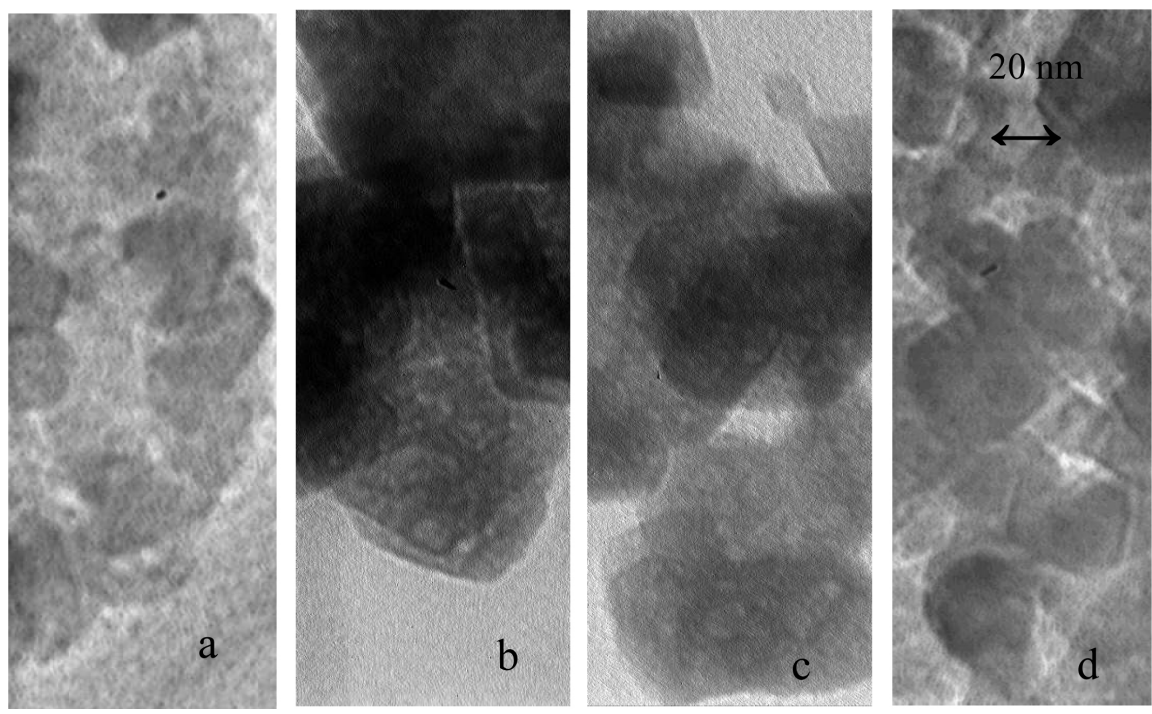

Figure 1. TEM images of powders synthesized at different conditions with different precursors according to Table 1: (a) A, (b) Z, (c) A20Z and (d) A50Z.

14. It can be seen from the chart that the order of photocatalytic activity of powders is $\mathrm{A} 20 \mathrm{Z}>\mathrm{A} 50 \mathrm{Z}>\mathrm{A}>\mathrm{Z}$ respectivly. Many papers on AOP claim that the photocatalytic efficiency of $\mathrm{TiO}_{2}$ depends on its phases [12], and crystalline size [13]. This variability has been attributed to difference in the levels of semiconductor, the rate of electron-hole recombination [14] [15], and adsorption and desorption behavior of surface sits [15]. The mobility of charge-carriers and electron hole pair's recombination rate are critical steps in the reaction rate. the band gaph of $\mathrm{ZnS}$ is about $3.54 \mathrm{ev}$ that could not contributed in this irradiation, and the Fermi level of $\mathrm{ZnS}$ is higher than anatase [1]. In mixed $\mathrm{ZnS}$ and anatase, sample (A) generally enhances the photocatalytic activity as seen in Table 2. This activity derived from the results of dye decolonization and water splitting tests. Thus, the surface of catalyst is the most effective structural parameter of kinetic in five step of reaction, because photocatalysis is an interfacial reaction. Thus, a higher specific surface area induces a higher number of accessible active sites. It has other effects on the $\mathrm{e}-\mathrm{h}+$ recombination time [15] band gap energy, penetration of light, consequently, photocatalyst reactivity. The band gaps of powders are related to their ledge of adsorption which is indicated in Table 2. 
The composite samples have shorter adsorption wavelength that is against the core and shell's band gap. Smaller 2D crystalline size of $\mathrm{ZnS}$ could show quantum size effect and broadening of adsorption range [16] but conductance and valance levels of two semiconductor indicated that electron and hole could transfer between these levels to decrease the band gap and recombination rate. Also, the surface charge of samples is collected in Table 2. The charge value for composite samples gradually exchanged from pure anatase to pure $\mathrm{ZnS}$. This shows that $\mathrm{ZnS}$ and $\mathrm{TiO}_{2}$ present on the surface area of composite. Increased reaction sites on the surface of the catalyst enhanced the reactivity.

The coupling or capping of two semiconductors provides a more efficient electron/hole separation, delayed charge recombination, and enhanced interfacial suitable sites [17] as shown in composite results. The summary table shows that this sample has good photodecolorization, it can be related to: 1) electron-hole transfer process (IPET) [16];2) increased surface sits.

Dye adsorption isotherms of powders show in Figure 2. The accumulation of the dye on the surface of $\mathrm{ZnS}$ is very low and on the anatase is limited, but on the composite samples is increased and not limited. The graphs for composite samples have some steps which indicate different mechanisms cooperated on the adsorption of dye on the surface sites.

\section{Conclusion}

In this study, photocatalytic activity of $\mathrm{TiO}_{2} / \mathrm{ZnS}$ nano composites has been investigated using two systems. The reaction rate was related to the surface area, phase's ratio, particle size, adsorption mechanism of reactants, concentration of dye and catalyst. The surface reaction sites and photo reactivity are higher in

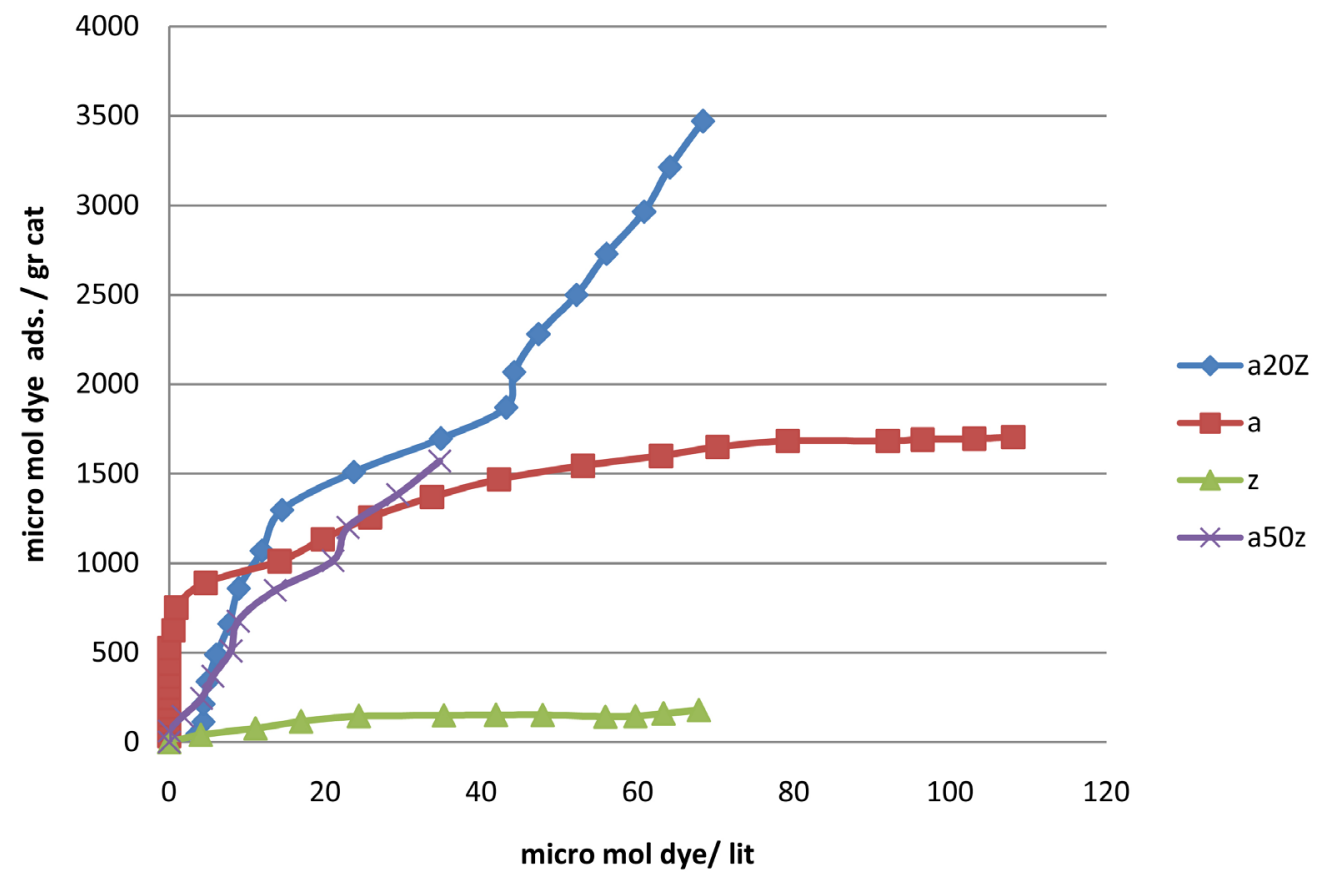

Figure 2. Accumulation of dye (AR14) adsorbed on powders. 
composite powders with similar particle size and band gap. The concentration of reactants (dye or water, $\mathrm{H}_{2}, \mathrm{O}_{2}$ ) is important because they react in suitable surface sites. The suitable sites are determined by size of compounds and surface charges. Additional to the surface properties, effectively charge separation increased the photo reactivity of composites.

\section{Acknowledgements}

The authors thank the Ministry of Science, Research and Technology of Iran and Iran Nano Society for financial support provided to do this research.

\section{References}

[1] Hoffmann, M.R., et al. (1995) Environmental Applications of Semiconductor Photocatalysis. Chemical Reviews, 95, 69-96. https://doi.org/10.1021/cr00033a004

[2] Kudo, A. (2006) Development of Photocatalyst Materials for Water Splitting. International Journal of Hydrogen Energy, 31, 197-202.

https://doi.org/10.1016/j.ijhydene.2005.04.050

[3] Fujishima, A., Zhang, X.T. and Tryk, D.A. (2008) $\mathrm{TiO}_{2}$ Photocatalysis and Related Surface Phenomena. Surface Science Reports, 63, 515-582. https://doi.org/10.1016/j.surfrep.2008.10.001

[4] Diebold, U. (2003) The Surface Science of Titanium Dioxide. Surface Science Reports, 48, 53-229. https://doi.org/10.1016/S0167-5729(02)00100-0

[5] Caruso, F. (2001) Nanoengineering of Particle Surfaces. Advanced Materials, 13, 11 22. https://doi.org/10.1002/1521-4095(200101)13:1<11::AID-ADMA11>3.0.CO;2-N

[6] Cushing, B.L., Kolesnichenko, V.L. and O’Connor, C.J. (2004) Recent Advances in the Liquid-Phase Syntheses of Inorganic Nanoparticles. Chemical Reviews, 104, 3893-3946. https://doi.org/10.1021/cr030027b

[7] Bawendi, M.G., et al. (1997) (CdSe)ZnS Core-Shell Quantum Dots: Synthesis and Characterization of a Size Series of Highly Luminescent Nanocrystallites. The Journal of Physical Chemistry B, 101, 9463-9475. https://doi.org/10.1021/jp971091y

[8] Peng, T.Y., Hasegawa, A., Qiu, J.R. and Hirao, K. (2003) Fabrication of Titania Tubules with High Surface Area and Well-Developed Mesostructural Walls by Surfactant-Mediated Templating Method. Chemistry of Materials, 15, 2011-2016. https://doi.org/10.1021/cm020828f

[9] Kim, S., Fisher, B., Eisler, H.-J. and Bawendi, M. (2003) Type-II Quantum Dots: $\mathrm{CdTe} / \mathrm{CdSe}(\mathrm{Core} / \mathrm{Shell})$ and $\mathrm{CdSe} / \mathrm{ZnTe}$ (Core/Shell) Heterostructures. Journal of the American Chemical Society, 125, 11466-11467. https://doi.org/10.1021/ja0361749

[10] Kolenko, Y.V., Maximov, V.D., Garshev, A.V., Meskin, P.E., Oleynikov, N.N. and Churagulov, B.R. (2004) Hydrothermal Synthesis of Nanocrystalline and Mesoporous Titania from Aqueous Complex Titanyl Oxalate Acid Solutions. Chemical Physics Letters, 388, 411-415. https://doi.org/10.1016/j.cplett.2004.03.042

[11] Fang, X.S., Zhai, T.Y., Gautam, U.K., Li, L., Wu, L.M., Bando, Y. and Golberg, D. (2011) ZnS Nanostructures: From Synthesis to Applications. Progress in Materials Science, 56, 175-287. https://doi.org/10.1016/j.pmatsci.2010.10.001

[12] Perumal, S. (2015) Photocatalytic Studies of Anatase and Rutile Phase $\mathrm{TiO}_{2} \mathrm{Nano-}$ crystals Prepared via Solvothermal Method. International Journal of Engineering Research and Applications, 5, 115-118. 
[13] Daneshvar, N., Salari, D. and Khataee, A.R. (2004) Photocatalytic Degradation of Azo Dye Acid Red 14 in Water on $\mathrm{ZnO}$ as an Alternative Catalyst to $\mathrm{TiO}_{2}$. Journal of Photochemistry and Photobiology A: Chemistry, 162, 317-322. https://doi.org/10.1016/S1010-6030(03)00378-2

[14] Chatterjee, D. and Dasgupta, S. (2005) Visible Light Induced Photocatalytic Degradation of Organic Pollutants. Journal of Photochemistry and Photobiology C: Photochemistry Reviews, 6, 186-205.

https://doi.org/10.1016/j.jphotochemrev.2005.09.001

[15] Crini, G. (2006) Non-Conventional Low-Cost Adsorbents for Dye Removal: A Review. Bioresource Technology, 97, 1061-1085. https://doi.org/10.1016/j.biortech.2005.05.001

[16] Gong, S., Yao, D., Feng, X. and Jiang, H. (2006) Quantum Size Dependent Optical Nutation in a Core-Shell CdSe/ZnS Quantum Dot. Microelectronics Journal, 37, 904-909. https://doi.org/10.1016/j.mejo.2006.01.015

[17] Ding, Z., Lu, G.Q. and Greenfield, P.F. (2000) Role of the Crystallite Phase of $\mathrm{TiO}_{2}$ in Heterogeneous Photocatalysis for Phenol Oxidation in Water. The Journal of Physical Chemistry B, 104, 4815-4820. https://doi.org/10.1021/jp993819b

Submit or recommend next manuscript to SCIRP and we will provide best service for you:

Accepting pre-submission inquiries through Email, Facebook, LinkedIn, Twitter, etc. A wide selection of journals (inclusive of 9 subjects, more than 200 journals)

Providing 24-hour high-quality service

User-friendly online submission system

Fair and swift peer-review system

Efficient typesetting and proofreading procedure

Display of the result of downloads and visits, as well as the number of cited articles

Maximum dissemination of your research work

Submit your manuscript at: http://papersubmission.scirp.org/

Or contact mrc@scirp.org 